\title{
11 - Indicadores e fatores contribuintes de incidentes
}

\author{
Celsa Raquel Villaverde Melgarejo \\ Patricia de Carvalho Mastroianni \\ Fabiana Rossi Varallo
}

\section{SciELO Books / SciELO Livros / SciELO Libros}

MELGAREJO, C. R. V., MASTROIANNI, P. C., and VARALLO, F. R. Indicadores e fatores contribuintes de incidentes. In: Promoção da cultura de notificação de incidentes em saúde [online]. São Paulo: Editora UNESP, 2019, pp. 53-84. ISBN: 978-85-9546-337-0.

https://doi.org/10.7476/9788595463370.0013.

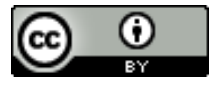

All the contents of this work, except where otherwise noted, is licensed under a Creative Commons Attribution 4.0 International license.

Todo o conteúdo deste trabalho, exceto quando houver ressalva, é publicado sob a licença Creative Commons Atribição 4.0.

Todo el contenido de esta obra, excepto donde se indique lo contrario, está bajo licencia de la licencia Creative Commons Reconocimento 4.0. 


\section{1 \\ INDICADORES E FATORES \\ CONTRIBUINTES DE INCIDENTES}

\section{Quedas}

A queda é considerada um indicador da qualidade da assistência prestada ao paciente, portanto, seu índice de ocorrência deve ser nulo, tornando, assim, o incidente um evento do tipo never event (Austin; Pronovost, 2015; The National Quality Forum, 2011).

A queda está associada a componentes multifatoriais decorrentes de uma complexa interação de fatores de riscos e é passível de ser prevenida, portanto traçar planos e reconhecer os fatores causais quando de sua ocorrência fazem parte da implementação de medidas e ações que contemplem a avaliação de risco do paciente.

As causas relacionadas a uma queda em ambiente hospitalar estão associadas a fatores definidos como intrínsecos, extrínsecos e comportamentais. Os fatores intrínsecos são entendidos como antecedentes de queda, idade superior a 60 anos ou crianças, relacionadas principalmente ao sexo feminino, ao uso de medicamentos psicoativos, diuréticos, distúrbios de marcha e equilíbrio, bem como ao estado nutricional, cognitivo, visual e deficiências ortopédicas. Dessa forma, os fatores intrínsecos estão diretamente associados aos fatores do próprio paciente, como contribuidor para o incidente queda, assim como os fatores comportamentais. De outro modo, os 
fatores extrínsecos estão associados aos riscos independentemente do paciente, como os ambientais, de execução, de equipe, dentre outros, como, por exemplo, ausência de grades no leito, degraus altos ou estreitos, inexistência de corrimão, problemas de iluminação, falta da campainha, altura do leito, disponibilidade de contenção (De Paiva et al., 2010; Ganz et al., 2007).

Fazendo uso das ferramentas de gestão da qualidade, Espinha de Peixe e Protocolo de Londres, é possível conhecer alguns fatores associados ao incidente quedas:

Quadro 8-Fatores contribuintes para ocorrência de quedas.

\begin{tabular}{|c|c|}
\hline Tipo de fator & Fator contribuinte ou influenciador \\
\hline Paciente & $\begin{array}{l}\text { Idade }>60 \text { anos ou crianças, estado nutricional (mal- } \\
\text { nutrido), comorbidades, comprometimento sensorial } \\
\text { e cognitivo, estado de consciência, histórico de queda, } \\
\text { uso de medicamentos (benzodiazepínicos, anti-hista- } \\
\text { mínicos, antidepressivos, relaxantes musculares, hi- } \\
\text { poglicemiante oral, polifarmácia, dentre outros), não } \\
\text { adesão ao protocolo de quedas, ausência de acompa- } \\
\text { nhantes. }\end{array}$ \\
\hline Tarefa & $\begin{array}{l}\text { Ausência ou não cumprimento de protocolos para pre- } \\
\text { venção de quedas. }\end{array}$ \\
\hline $\begin{array}{l}\text { Individuais } \\
\text { (profissional da } \\
\text { saúde) }\end{array}$ & $\begin{array}{l}\text { Não realizar a avaliação adequada para o risco de queda } \\
\text { do paciente (uso de escalas); não explicar ao paciente o } \\
\text { risco de queda e sua consequência; deixar as grades de } \\
\text { proteção abaixadas; não realização da escala de quedas } \\
\text { de morse. }\end{array}$ \\
\hline Equipes & $\begin{array}{l}\text { Falhas na comunicação; trocas de plantão incompletas } \\
\text { ou apressadas, não cumprimento de protocolos insti- } \\
\text { tucionais. }\end{array}$ \\
\hline $\begin{array}{l}\text { Ambientais e de } \\
\text { trabalho }\end{array}$ & $\begin{array}{l}\text { Ausência de grades no leito, ausência de campainhas ou } \\
\text { com mau funcionamento, falta da cadeira para banho, } \\
\text { cama destravada, chão molhado, iluminação fraca ou } \\
\text { com problemas. }\end{array}$ \\
\hline $\begin{array}{l}\text { Gestão } \\
\text { organizacional e } \\
\text { institucional }\end{array}$ & $\begin{array}{l}\text { Falta de recurso no investimento de novas tecnologias, } \\
\text { ausência de campanhas, treinamentos para a prevenção } \\
\text { de quedas, grupo de discussão sobre riscos de queda. }\end{array}$ \\
\hline
\end{tabular}

Fonte: Paiva et al. (2010); Ganz et al. (2007); Boushon et al. (2012). 
Segundo dados recentes, 16\% das notificações recebidas pela Anvisa são referentes à queda, sendo que $40 \%$ delas ocorrem no leito devido à perda de equilíbrio ou por escorregar (Anvisa, 2015).

\section{Flebite}

A flebite é uma inflamação do endotélio venoso ou arterial podendo ser classificada como mecânica, química ou bacteriana. A flebite mecânica está associada ao dispositivo invasivo que é utilizado ou a má fixação desse dispositivo, podendo provocar atrito na parede do vaso, uma vez que não está fixado adequadamente.

A flebite química é inerente às características físico-químicas do fármaco administrado ao paciente, isto é, a indústria farmacêutica utiliza técnicas como alteração de $\mathrm{pH}$ e osmolaridade para manter a estabilidade e a efetividade do princípio ativo de certos medicamentos, fato que os torna irritantes ou vesicantes. Já a flebite bacteriana é decorrente, principalmente, da falta de assepsia adequada, contribuindo para a proliferação de microrganismos, levando à infecção. Os sinais e sintomas da flebite são característicos, tais como, vermelhidão, dor, desconforto local e edema. Segundo as normas da Infusion Nurse Society (INS), a taxa aceitável para a ocorrência de flebite é de 5\% (Milutinović; Simin; Zec, 2015).

A flebite, assim como outros incidentes, pode ser prevenida. Entretanto, no caso da flebite química, pelas características intrínsecas do fármaco, torna-se difícil a prevenção quando os medicamentos flebogênicos são utilizados (Milutinović; Simin; Zec, 2015; Salgueiro-Oliveira; Parreira; Veiga, 2012).

Conhecer o $\mathrm{pH}$, a osmolaridade, o volume mínimo de infusão e diluição, bem como a velocidade de infusão, o gotejamento, dentre outros parâmetros, pode contribuir para a prevenção de incidentes como a flebite. Assim, os principais fatores relacionados à ocorrência de flebites são: 
Quadro 9-Fatores contribuintes para a ocorrência de flebite.

\begin{tabular}{|c|c|}
\hline Tipo de fator & Fator contribuinte ou influenciador \\
\hline Paciente & $\begin{array}{l}\text { Idade > } 60 \text { anos, rede venosa comprometida, condição } \\
\text { clínica, pré-disposição (tabagismo, problemas vascu- } \\
\text { lares), comorbidades (doenças vasculares, hipertensão } \\
\text { arterial, imunodepressão), maior propensão no sexo fe- } \\
\text { minino. }\end{array}$ \\
\hline Tarefa & $\begin{array}{l}\text { Ausência ou não cumprimento de protocolos para pre- } \\
\text { venção de flebites, dificuldade da avaliação da rede ve- } \\
\text { nosa. }\end{array}$ \\
\hline $\begin{array}{l}\text { Individuais } \\
\text { (profissional da } \\
\text { saúde) }\end{array}$ & $\begin{array}{l}\text { Não ter conhecimento e habilidades suficientemente } \\
\text { necessárias para a manutenção de dispositivos intra- } \\
\text { venosos e características físico-químicas de medica- } \\
\text { mentos administrados, escolha do local adequado para } \\
\text { inserção do cateter venoso periférico, calcular e estabele- } \\
\text { cer erroneamente o tempo necessário para infusão e sua } \\
\text { velocidade, não higienização, manutenção e fixação dos } \\
\text { cateteres, tempo de permanência do acesso venoso peri- } \\
\text { férico (AVP) acima do recomendado (72-96 h), escolha } \\
\text { inadequada do tipo de cateter, tempo de garroteamento. }\end{array}$ \\
\hline Equipes & $\begin{array}{l}\text { Falhas na comunicação, passagem de plantão inadequa- } \\
\text { da, desatenção do momento oportuno de transição de } \\
\text { medicamentos endovenosos (EV) para via oral (VO). }\end{array}$ \\
\hline $\begin{array}{c}\text { Ambientais e de } \\
\text { trabalho }\end{array}$ & $\begin{array}{l}\text { Carga excessiva de trabalho, tipo e material do cateter, } \\
\text { tipo de cobertura na fixação do cateter, integridade e hi- } \\
\text { giene do AVP. }\end{array}$ \\
\hline $\begin{array}{l}\text { Gestão } \\
\text { organizacional e } \\
\text { institucional }\end{array}$ & Falta de recurso no investimento de novas tecnologias. \\
\hline
\end{tabular}

Fonte: Milutinović; Simin; Zec (2015); O'Grady et al. (2011); Salgueiro-Oliveira; Parreira; Veiga (2012).

\section{Lesão por pressão (LPP)}

A lesão por pressão é definida como uma lesão cutânea ou de partes moles superficiais ou profundas localizadas em proeminências ósseas. Sabe-se que a lesão quando adquirida na instituição de saúde pode levar a um aumento médio de 3 a 4 dias de internação, elevando custos de tratamento e demais despesas de hospedagem. Estima-se 
que nos Estados Unidos da América (EUA), os gastos variam entre 2.000 e 70.000 dólares por paciente com o tratamento desse evento.

A partir do consenso ocorrido em abril de 2016 do National Pressure Ulcer Advisory Panel (NPUAP), organização sem fins lucrativos, que se dedica à prevenção e tratamentos de lesões de pele nos Estados Unidos, foram propostas mudanças na terminologia e definições do estadiamento das lesões, pois elas são categorizadas de acordo com a extensão do dano do tecido. O que antigamente era nomeado como escara ou úlceras de decúbito, hoje recebe a nomenclatura de lesão por pressão.

Quadro 10 - Classificação das lesões por pressão segundo o NPUAP.

\begin{tabular}{cl}
\hline Lesão por pressão & \multicolumn{1}{c}{ Definição } \\
\hline Grau I & Pele íntegra com eritema que não embranquece. \\
\hline Grau II & $\begin{array}{l}\text { Perda da pele em sua espessura parcial com exposição } \\
\text { da derme. }\end{array}$ \\
\hline Grau III & Perda da pele em sua espessura total. \\
\hline Grau IV & Perda da pele em sua espessura total e perda tissular. \\
\hline Não classificável & $\begin{array}{l}\text { Perda da pele em sua espessura total e perda tissular } \\
\text { não visível. }\end{array}$ \\
\hline $\begin{array}{c}\text { Tissular profunda } \\
\text { Coloração vermelho-escura, marrom ou púrpura, } \\
\text { persistente e que não embranquece. }\end{array}$ \\
\hline $\begin{array}{c}\text { Relacionada ao } \\
\text { uso de dispositivos } \\
\text { médicos }\end{array}$ & $\begin{array}{l}\text { Resultante do uso de dispositivos criados e aplicados } \\
\text { para fins diagnósticos e terapêuticos. Este tipo de lesão } \\
\text { geralmente apresenta o mesmo formato do dispositivo } \\
\text { utilizado. }\end{array}$ \\
\hline $\begin{array}{c}\text { Em membranas } \\
\text { mucosas }\end{array}$ & $\begin{array}{l}\text { Encontrada quando há histórico de uso de dispositivo } \\
\text { médico no local da lesão. }\end{array}$ \\
\hline $\begin{array}{c}\text { Relacionada ao } \\
\text { uso de utensílios } \\
\text { domésticos }\end{array}$ & $\begin{array}{l}\text { Resultante do contato prolongado com cadeiras ou } \\
\text { leitos, isto é, objetos relativos ao paciente restrito. }\end{array}$ \\
\hline
\end{tabular}

Fonte: National Pressure Ulcer Advisory Panel, 2014.

A lesão por pressão de grau III e IV é considerada never events, um dos indicadores de qualidade dos serviços pela Agency for Healthcare Research and Quality (Shekelle et al., 2013). 
Traçando a análise de causas usando o diagrama de Ishikawa (Espinha de Peixe), os principais fatores de LPP são:

Quadro 11 - Fatores contribuintes para ocorrência de LPP.

\begin{tabular}{|c|c|}
\hline Tipo de fator & Fator contribuinte ou influenciador \\
\hline Paciente & $\begin{array}{l}\text { Condição física: extremos de pesos; dificuldade para } \\
\text { realizar mudança de decúbito a cada } 2 \text { horas; caquexia, } \\
\text { paciente muito debilitado e provavelmente com alguma } \\
\text { proeminência óssea; condição clínica (comorbidades as- } \\
\text { sociadas: diabetes, neuropatias, tabagismo, edema, al- } \\
\text { terações metabólicas); estado nutricional; higienização } \\
\text { corporal inadequada; integridade da pele, paciente que } \\
\text { já tem ou com histórico anterior de LPP. }\end{array}$ \\
\hline Tarefa & $\begin{array}{l}\text { Ausência ou não cumprimento de protocolos para pre- } \\
\text { venção de LPP, protocolos mal elaborados, desenho da } \\
\text { tarefa com falta de clareza e objetividade. }\end{array}$ \\
\hline $\begin{array}{l}\text { Individuais } \\
\text { (profissional da } \\
\text { saúde) }\end{array}$ & $\begin{array}{l}\text { Ausência de capacitação do profissional em reconhe- } \\
\text { cer uma LPP, não utilização da escala de Braden ou es- } \\
\text { tratificação de riscos, não cumprimento da mudança } \\
\text { de decúbito a cada } 2 \text { horas, imobilização inadequada } \\
\text { do paciente; falta de conscientização dos profissionais } \\
\text { em prevenir uma lesão, não conhecer as medidas pre- } \\
\text { ventivas. }\end{array}$ \\
\hline
\end{tabular}

\begin{tabular}{cl}
\hline Equipes & $\begin{array}{l}\text { Falhas na comunicação, passagem de plantão inadequa- } \\
\text { da, não registro em prontuário, registro inadequado ou } \\
\text { incompleto. }\end{array}$ \\
\hline $\begin{array}{c}\text { Ambientais e de } \\
\text { trabalho }\end{array}$ & $\begin{array}{l}\text { Quantidade reduzida de profissionais para realizar mu- } \\
\text { dança de decúbito; escassez de dispositivos, como col- } \\
\text { chões pneumáticos, casca de ovo, rede de jack, coxins; } \\
\text { falta de pomadas e cremes para hidratação e regenera- } \\
\text { ção da pele. }\end{array}$ \\
\hline
\end{tabular}

\begin{tabular}{cl}
\hline $\begin{array}{c}\text { Gestão } \\
\text { organizacional e } \\
\text { institucional }\end{array}$ & $\begin{array}{c}\text { Falta de apoio organizacional, baixa adesão dos profis- } \\
\text { sionais no grupo de gerenciamento de curativos. }\end{array}$ \\
\hline
\end{tabular}

Fonte: Campanili et al. (2015); Coleman et al. (2013); Sving et al. (2014); Villar-Patón et al. (2013).

O estadiamento (grau da lesão) e onde surgiu a lesão são dados que merecem destaque na LPP. Sabe-se que há lesões adquiridas em ambiente hospitalar tendo início no grau I, e existem aquelas provenientes de outros locais, como domiciliar e outras instituições 
hospitalares (transferências), em que o paciente já chega acometido pela LPP.

É de extrema importância o cuidado que se deve ter com a lesão advinda de outro local, pois sua evolução, ou seja, aumento do grau, está diretamente relacionado com o cuidado e a conduta profissional quanto ao manejo das lesões e medidas de prevenção, refletindo assim na credibilidade da instituição e na reputação do profissional, uma vez que a observação e identificação de piora da LPP remete a um cuidado insuficiente e ineficaz do paciente.

Portanto, o detalhamento dos incidentes com seus possíveis fatores causais resulta em uma notificação mais estruturada capaz de fornecer subsídios à gestão de riscos para a promoção da qualidade nos serviços de saúde e prevenção quanto à ocorrência da LPP.

\section{Identificação correta de pacientes}

A identificação correta do paciente está prevista na Lei n. 10.241, de 17 de março de 1999, e dispõe sobre os direitos dos pacientes e usuários dos serviços de saúde no Estado de São Paulo. É o processo pelo qual se assegura que o cuidado seja prestado ao paciente para qual se destina. Falhas na identificação podem ocorrer desde o momento da admissão do paciente até a alta hospitalar, ou seja, em todas as fases da assistência.

O cuidado, no que diz respeito à identificação do paciente, também envolve profissionais que não estão ligados diretamente com a assistência à saúde do paciente em ambiente hospitalar, como recepcionistas, porteiros, secretários.

Uma falha no nome, na data de nascimento, ou outras informações relevantes no momento da admissão, faz com que aumente os riscos nos processos de cuidados posteriores à entrada do paciente no hospital (Smith et al., 2011), pois, a partir disso, erros em cadeia podem ocorrer, como nas etapas de prescrição ou dispensação de algum medicamento, em exames diagnósticos e complementares, na liberação do tipo de dieta etc. Outros fatores que podem induzir ao 
erro é a não familiaridade com nomes advindos de outras culturas, dificultando a pronúncia e até mesmo a escrita e, consequentemente, sua checagem a cada procedimento (Tase et al., 2013).

A educação e conscientização dos profissionais é algo que merece atenção e destaque para valorizar cada etapa de cuidado do paciente, pois a prática de verificação da identificação às vezes se torna algo sem importância quando se trata de pacientes que estão internados por longo período na instituição (Tase et al., 2013).

A identificação incorreta do paciente, que resulta em dano grave ou óbito, também é considerada um never event (Shekelle et al., 2013).

Dados nacionais indicam que erros na identificação do paciente são decorrentes da falta de uso da pulseira $(60,3 \%)$ e da falta da identificação no leito (18\%) (Anvisa, 2016). A porcentagem de pacientes identificados corretamente deve ser próxima de $100 \%$, pois é considerada indicador da qualidade da assistência em saúde (Neves; Melgaço, 2007).

Uma comunicação efetiva entre equipes pode prevenir trocas de nomes de pacientes, assim como qualquer outro tipo de incidente. Por conseguinte, a maneira como ocorre a comunicação entre profissionais de saúde tem contribuído para causar erros que poderiam ser evitáveis, fato que diminui a qualidade no cuidado. Dentre os principais motivos para que a comunicação se torne falha, está a diversidade de formação dos profissionais e a diferença de níveis hierárquicos (Nogueira; Rodrigues, 2015).

A omissão de dados importantes, a falta de precisão ou inconsistência na informação repassada são as principais falhas observadas na passagem de plantão entre equipes. A fim de reduzir e corrigir as falhas na comunicação, lança-se mão do uso de uma ferramenta denominada SBAR (The Joint Commission International, 2007; WHO, 2007).

OSBARé uma padronização de informações sobre o paciente, que permite assegurar a transferência de informações de maneira correta e completa (Johnson; Kimsey, 2012). A sigla deriva dos componentes essenciais e fornece estrutura necessária para que haja comunicação efetiva entre os profissionais. A leta "S" refere-se à situação, havendo 
necessidade de apresentação breve do interlocutor ao informar a razão do chamado ou a situação do momento. "B", de background, corresponde a segunda letra da sigla, é o momento em que todo o histórico do paciente é relatado verbalmente, do diagnóstico da admissão ao tratamento atual. "A", de assessment, avaliação, corresponde ao que mudou com relação ao cuidado do paciente, bem como sua condição clínica, resultados de exames etc.; e o "R", recommendation, refere-se às recomendações necessárias (Achrekar et al., 2016).

Ademais, a taxa de erros referentes à pulseira de identificação deve ser considerada entre 0,2 a $0,3 \%$ (Smith et al., 2011). Por isso é de suma importância a conferência frequente dos estratificadores com o próprio paciente, fazendo-o falar seu nome e sua data de nascimento. Em casos inviáveis as informações devem ser checadas com familiares e acompanhantes e, na ausência destes, deve-se conferir os dados com os da pulseira de identificação do paciente.

Em casos de pacientes homônimos, deve-se realizar a conferência do nome da genitora e do número de identificação do prontuário da instituição de saúde (quando houver).

Os mecanismos associados a não identificação correta do paciente incluem:

Quadro 12 - Fatores contribuintes para a falha na identificação do paciente.

\begin{tabular}{cl}
\hline Tipo de fator & \multicolumn{1}{c}{ Fator contribuinte ou influenciador } \\
\hline Paciente & $\begin{array}{l}\text { Não adesão ao uso de pulseira de identificação, pacien- } \\
\text { tes homônimos, estado clínico (confusão mental, mem- } \\
\text { bros amputados, com queimaduras), falta ou ausência } \\
\text { do acompanhante. }\end{array}$ \\
\hline Tarefa & $\begin{array}{l}\text { Indisponibilidade de adesão aos protocolos, não } \\
\text { padronização das condutas para identificação correta do } \\
\text { paciente. }\end{array}$ \\
\hline $\begin{array}{c}\text { Individuais } \\
\text { (profissional da } \\
\text { saúde) }\end{array}$ & $\begin{array}{l}\text { Não uso de estratificadores para identificação, como } \\
\text { nome da mãe e data de nascimento; maneira inadequada } \\
\text { quada da identificação a cada procedimento, adminis- } \\
\text { tração de medicamentos, hemoderivados, coleta de } \\
\text { exame, entrega da dieta, procedimentos invasivos; não } \\
\text { confirmação de quarto; pulseira de identificação e leito. }\end{array}$ \\
\hline &
\end{tabular}




\begin{tabular}{cl}
\hline Tipo de fator & \multicolumn{1}{c}{ Fator contribuinte ou influenciador } \\
\hline Equipes & $\begin{array}{l}\text { Falhas ao receber pacientes de transferências e na pas- } \\
\text { sagem de plantão (SBAR); falta de educação conti- } \\
\text { nuada e conscientização das equipes para valorizar a } \\
\text { confirmação correta dos dados do paciente, sobretudo } \\
\text { àqueles internados por longos períodos. }\end{array}$ \\
\hline $\begin{array}{c}\text { Técnicos de enfermagem responsáveis pelo cuidado de } \\
\text { dois ou mais pacientes ao mesmo tempo e com mesmo } \\
\text { nome; número reduzido de profissionais; pulseira de } \\
\text { trabalho } \\
\text { identificação com escrita ou números errados; placa da } \\
\text { cabeceira do leito com nome ilegível ou apagado ou com } \\
\text { nome de algum paciente que já tenha tido alta hospi- } \\
\text { talar; dados incompletos na pulseira de identificação, } \\
\text { letras e números semelhantes. }\end{array}$ \\
$\begin{array}{c}\text { Gestão } \\
\text { organizacional e } \\
\text { institucional }\end{array}$ & $\begin{array}{l}\text { Fornecer instrumentos adequados para identificação do } \\
\text { paciente (pulseiras com tamanho adequado e confortá- } \\
\text { veis, etiquetas duráveis e laváveis, boa técnica de im- } \\
\text { pressão, letras legíveis). }\end{array}$ \\
\hline
\end{tabular}

Fonte: Avelar (2010;) Franco et al. (2010); Howanitz; Renner; Walsh (2002); Mayor (2007); Oliveira et al. (2014); Pablo-Comeche; Buitrago-Vera; Meneu (2010); Smith et al. (2011); Thorpy et al. (2007); Vandenbroucke (2001); WHO (2009).

\section{Cirurgia segura}

O Segundo Desafio Global da OMS prevê o desenvolvimento de uma lista de verificação para a promoção da segurança do paciente em procedimentos cirúrgicos. O objetivo é estabelecer padronização de normas durante o ato cirúrgico, composta de três etapas denominadas checklist de cirurgia segura, quais sejam, antes de iniciar a anestesia (sign in), antes de iniciar a incisão cirúrgica e após o término do procedimento (time out) e antes do paciente deixar a sala de cirurgia (sign out) (Pancieri et al., 2013; Weerakkody et al., 2013).

$\mathrm{O}$ ambiente cirúrgico é considerado altamente inseguro e de acordo com dados da National Health System (NHS), a maioria das queixas vêm da especialidade cirúrgica (OMS, 2009). Estima-se que metade dos procedimentos cirúrgicos realizados acarretam complicações graves (never event), sendo que 50\% desses eventos poderiam ter sido evitados. Assim, faz-se necessário estabelecer normas e 
investigar as causas possíveis para prevenir danos. Procedimentos cirúrgicos realizados em locais, em pacientes e em lateralidade errados, além do esquecimento de objetos e/ou materiais no corpo do paciente, que venha a resultar em dano grave ou evoluam para óbito, fazem parte da lista de never events em cirurgia (OMS, 2009; Pancieri et al., 2013; The Canadian Patient Safety Institute, 2015; Weerakkody et al., 2013).

Não somente os erros em cirurgia devem ser prevenidos, mas também os riscos associados à ocorrência de infecções em sítios cirúrgicos. Tais riscos estão associados às condições clínicas e físicas do paciente, como diabetes, devido às complicações fisiopatológicas durante o processo de cicatrização, fragilidade no sistema imunológico e problemas vasculares característico da doença (Bellusse et al., 2015), assim como a obesidade, em razão de maior espessura da camada corpórea (Antoniali et al., 2005; WHO, 2016), além dos riscos relativos à conduta no próprio procedimento, que são classificados como fatores exógenos, como a correta esterilização/ descontaminação de instrumentos cirúrgicos e uso de materiais de prevenção, dentre eles, gorros, luvas estéreis, máscaras e, principalmente, a correta assepsia de mãos e pertences de toda a equipe envolvida no procedimento cirúrgico (WHO, 2016). Garantir o contato mínimo da equipe cirúrgica com outros locais ou objetos (maçanetas, portas, janelas, tecla de computador, piso) que podem ser fontes de contaminação por microrganismos patogênicos é um cuidado a mais recomendado em procedimentos cirúrgicos (WHO, 2016). As reabordagens cirúrgicas também podem ser fontes de infecção, visto que no momento em que o paciente é submetido novamente à cirurgia, as chances de adquirir contaminação bacteriana aumenta.

A antibioticoterapia deve ser eficaz no controle das infecções, principalmente quando se trata de procedimento cirúrgico, para isso a Comissão de Controle de Infecção Hospitalar (CCIH) deve estar munida de protocolos e condutas que possam garantir o controle das infecções provenientes da equipe cirúrgica. É relevante que os conhecimentos não fiquem centrados na $\mathrm{CCIH}$, mas que haja 
divulgação eficiente conduzindo a uma prática constante dos protocolos de profilaxia para a infecção de sítio cirúrgico.

A profilaxia com antibióticos varia de acordo com o recomendado por cada instituição, embora a utilização adequada de antibióticos seja de 30 a 60 minutos antes da incisão cirúrgica, com duração máxima de 24 horas após o procedimento cirúrgico (Bratzler et al., 2013).

Um fato importante é o turn over, definido como o tempo entre a saída de um paciente da sala cirúrgica e a entrada de outro, pois entre uma cirurgia e outra deve ser feita uma limpeza total do ambiente, assim como o preparo (medicamentos, kits cirúrgicos, instrumentos, anestesia) exigido para o próximo paciente. Quanto maior o tempo de duração da cirurgia, maior a exposição da ferida do paciente ao ambiente, contribuindo para futuras complicações pós-operatórias (Bellusse et al., 2015).

O turn over depende muito da equipe multidisciplinar como um todo (enfermeiros, farmacêuticos, médicos, equipe de limpeza), assim como do tipo de instituição onde é feito o procedimento cirúrgico, no que se refere ao volume de procedimentos cirúrgicos que a instituição comporta, dependendo de sua complexidade (alta, média e baixa) (Jericó; Perroca; Penha, 2011).

Algumas causas envolvidas em erros cirúrgicos estão listadas a seguir:

Quadro 13 - Fatores contribuintes para erros em cirurgia.

\begin{tabular}{cl}
\hline Tipo de fator & \multicolumn{1}{c}{ Fator contribuinte ou influenciador } \\
\hline Paciente & $\begin{array}{l}\text { Condição física emocional para realização da cirurgia, } \\
\text { preparo adequado para a cirurgia, jejum. }\end{array}$ \\
\hline Tarefa & $\begin{array}{l}\text { Não cumprimento de protocolos, falta de avaliação de } \\
\text { riscos, não adesão ao checklist proposto pela OMS ou } \\
\text { pela instituição. }\end{array}$ \\
\hline $\begin{array}{c}\text { Individuais } \\
\text { (profissional da } \\
\text { saúde) }\end{array}$ & $\begin{array}{l}\text { Principalmente o não cumprimento dos itens que com- } \\
\text { põe o checklist de cirurgia segura, ausência de habilida- } \\
\text { des e conhecimentos. }\end{array}$ \\
\hline Equipes & Falhas na comunicação verbal e escrita e entre equipes. \\
\hline
\end{tabular}




\begin{tabular}{cl}
\hline Tipo de fator & \multicolumn{1}{c}{ Fator contribuinte ou influenciador } \\
\hline $\begin{array}{c}\text { Ambientais e de } \\
\text { trabalho }\end{array}$ & $\begin{array}{l}\text { Falta de equipamentos, materiais e instrumentos ade- } \\
\text { quados ao tipo de cirurgia, sobrecarga de trabalho, } \\
\text { número reduzido de profissionais, bom relacionamento } \\
\text { entre equipes. }\end{array}$ \\
\hline $\begin{array}{c}\text { Gestão } \\
\text { organizacional e } \\
\text { institucional }\end{array}$ & $\begin{array}{c}\text { Falta de ações, políticas, campanhas, treinamentos e re- } \\
\text { cursos financeiros aplicáveis à especialidade cirúrgica. }\end{array}$ \\
\hline
\end{tabular}

Fonte: Motta Filho et al. (2013); Opas (2009); WHO (2016); Pancieri et al. (2013).

Com o intuito de reforçar o objetivo de uma cirurgia mais segura, além do checklist, a OMS também estabeleceu dez objetivos fundamentais, tendo como base o checklist (OMS, 2009):

- cirurgia no paciente certo e no local correto;

- utilização de métodos conhecidos para evitar danos na administração de anestésicos, protegendo o paciente da dor;

- avaliação da via aérea;

- avaliação de risco de perda sanguínea;

- avaliação de reações alérgicas;

- utilização de métodos conhecidos para minimizar o risco de infecção no sítio cirúrgico;

- checagem para não esquecer instrumentos e compressas dentro do paciente;

- identificação correta e segura de todos os materiais utilizados no procedimento;

- comunicação segura e eficaz durante a cirurgia;

- estabelecimento de vigilância constante na quantidade de procedimentos cirúrgicos com posterior análise pela instituição de saúde.

A prevenção de infecções do sítio cirúrgico (ISCs) também é um processo de cuidado importante, visto que há alta prevalência de procedimentos cirúrgicos em todo o mundo. As ISCs são definidas como infecções nos locais de incisões ou órgãos que foram submetidos à cirurgia (CDC, 2017). 
Dados na literatura indicam que aproximadamente metade das ISCs são evitáveis e levam ao aumento de custos financeiros e de recursos humanos para as instituições de saúde, no que diz respeito ao tratamento. Diante do exposto, o Center of Disease Control (CDC), agência de prevenção e controle de doenças contagiosas dos Estados Unidos, lançou, em agosto de 2017, diretrizes baseadas em revisão sistemática com o intuito de fornecer recomendações atualizadas e científicas como medidas de prevenção e controle de doenças e infecções em sítios cirúrgicos (Berríos-Torres et al., 2017).

\section{Infecção de corrente sanguínea}

As infecções primárias de corrente sanguínea (IPCS) estão diretamente relacionadas à assistência à saúde. Dentre os riscos para desenvolver uma IPCS, estão o uso de cateteres venoso centrais e periféricos e complicações decorrentes de procedimentos cirúrgicos (WHO, 2016). É importante estabelecer medidas de prevenção, visto que a IPCS está relacionada ao aumento a taxa de mortalidade, maior tempo de internação e aumento de recursos para o tratamento, elevando o custo para a instituição.

Quanto à fisiopatogenia da infecção, alguns itens devem ser reforçados: avaliação da integridade da pele do paciente; assepsia correta das mãos, tanto do profissional quanto do paciente; contaminação do líquido infundido; dispositivos e conectores não esterilizados corretamente; contaminação ou migração de microbiota de um sítio não higienizado a outro durante a indução de dispositivos.

As barreiras máximas para prevenção de IPCS são o uso de gorros; luvas estéreis; avental; preparo da pele; seleção do sítio de inserção do cateter venoso central (CVC), com preferência para a subclávia; revisão diária da permanência do dispositivo no paciente, sua integridade e higiene. 
Figura 2 - Esquema ilustrativo da fisiopatogenia das infecções de corrente sanguínea.

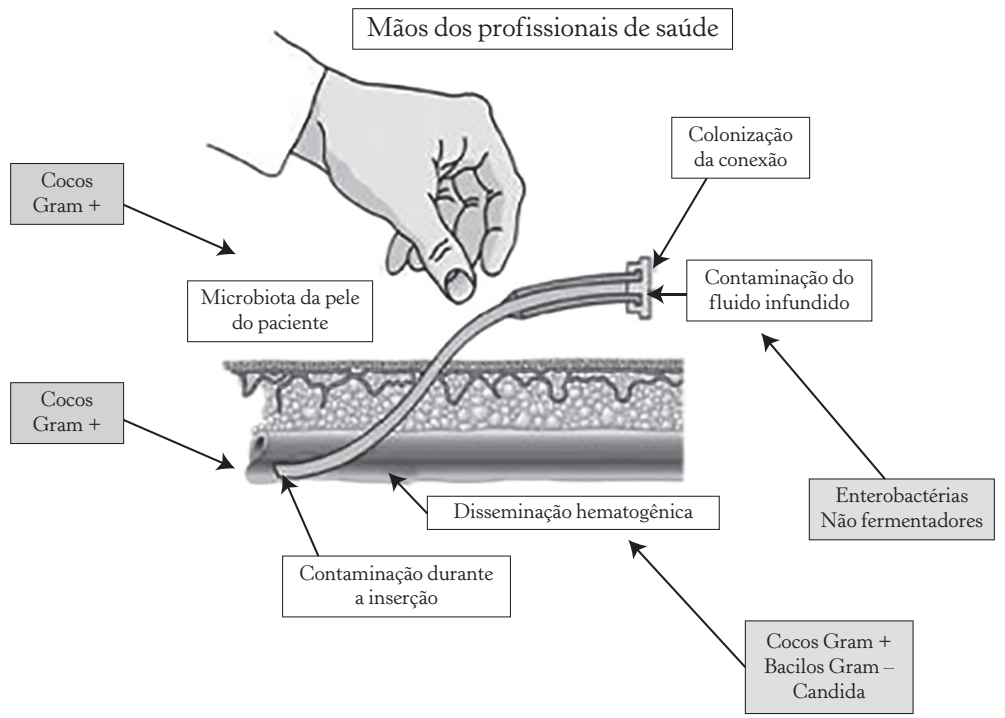

Fonte: Anvisa (2017). Disponível em: Maki (1992)

Os fatores associados à IPCS descritos na literatura são:

Quadro 14 - Fatores contribuintes para infecção de corrente sanguínea.

\begin{tabular}{cl}
\hline Tipo de fator & \multicolumn{1}{c}{ Fator contribuinte ou influenciador } \\
\hline Paciente & $\begin{array}{l}\text { Condição clínica (queimadura, resistência à antibioti- } \\
\text { coterapia, neutropenia), não adesão às orientações de } \\
\text { cuidado com uso de dispositivos, não afeito à higiene. }\end{array}$ \\
\hline Tarefa & $\begin{array}{l}\text { Falha na comunicação entre equipes, insubordinação, } \\
\text { protocolos não estruturados ou bem descritos. }\end{array}$ \\
\hline $\begin{array}{c}\text { Individuais } \\
\text { (profissional da } \\
\text { saúde) }\end{array}$ & $\begin{array}{l}\text { mento realizado, não desinfecção de conectores an- } \\
\text { tes de serem inseridos, não avaliação da higienização } \\
\text { do dispositivo, não realizar a troca do curativo confor- } \\
\text { me recomendação, manipulação excessiva de cateteres } \\
\text { (hub), permanência prolongada do mesmo cateter sem }\end{array}$ \\
& $\begin{array}{l}\text { a avaliação de enfermeiros, infusão de soluções conta- } \\
\text { minadas decorrente da prática inadequada de preparo. }\end{array}$ \\
\hline
\end{tabular}




\begin{tabular}{cl}
\hline Equipes & $\begin{array}{l}\text { Falhas na comunicação verbal e escrita e entre equipes, } \\
\text { ausência do controle da CCIH. }\end{array}$ \\
\hline $\begin{array}{c}\text { Ambientais e de } \\
\text { trabalho }\end{array}$ & $\begin{array}{l}\text { Falta de materiais e instrumentos adequados ao tipo de } \\
\text { cobertura (recurso de má qualidade que não protege o } \\
\text { acesso venoso ou o local de inserção do dispositivo in- } \\
\text { vasivo), fixação de dispositivo, sobrecarga de trabalho, } \\
\text { número reduzido de profissionais, bom relacionamento } \\
\text { entre equipes. }\end{array}$ \\
\hline $\begin{array}{c}\text { Gestão } \\
\text { organizacional e }\end{array}$ & $\begin{array}{l}\text { Falta de ações, políticas, campanhas treinamentos e re- } \\
\text { cursos financeiros para promover a redução de IPCS, } \\
\text { como recursos para prover contratação suficiente de } \\
\text { profissionais e a disponibilização de dispositivos ade- } \\
\text { quados (fixadores); inefetividade da ação da CCIH; } \\
\text { não promoção de medidas educativas para o controle } \\
\text { da infecção. }\end{array}$ \\
\hline
\end{tabular}

Fonte: Anvisa (2017); WHO (2016); O’Grady et al. (2011); Berenholtz et al. (2004).

\section{Incidentes relacionados ao uso de medicamentos}

Os incidentes estão relacionados aos agravos de saúde manifestados durante o tratamento, geralmente associados ao uso de medicamentos. Ressalta-se que outros insumos farmacêuticos também podem desencadeá-los, quais sejam, qualquer substância química ativa com propriedades farmacológicas com finalidade medicamentosa utilizada para alívio, tratamento e diagnóstico, como fitoterápicos e contrastes em exames de imagem, dentre outras finalidades.

O monitoramento da ocorrência de incidentes, por meio da farmacovigilância, pode auxiliar a minimizar possíveis efeitos negativos relacionados ao uso de medicamentos em pacientes (Mendes; Martins; Rozenfeld, 2009).

A farmacovigilância consiste em atividades de detecção, avaliação, compreensão e prevenção de qualquer incidente ou problema que estejam relacionados aos medicamentos, tendo como uma de suas ações a notificação voluntária desses incidentes em ambiente hospitalar (Martins et al., s.d.; OMS, 2005b).

Problemas com medicamentos incluídos na prática da farmacovigilância são definidos pela OMS, como o uso off label (uso de 
medicamentos fora do recomendado), venda ilegal de drogas pela internet e abuso, fabricação e venda de medicamentos falsificados, prática da automedicação e uso crescente de medicamentos com potencial para causar interação medicamentosa (OMS, 2005b).

Apesar de a OMS ter ampliado o escopo da farmacovigilância, conforme referido anteriormente, os principais incidentes relacionados aos medicamentos ainda incluem erros de medicação (EM), reações adversas aos medicamentos (RAM), inefetividade terapêutica (IT) e desvio da qualidade de medicamento/queixas técnicas (DQM) (Varallo; Mastroianni, 2013b).

Figura 3 - Esquema ilustrativo dos incidentes relacionados ao uso de medicamentos.

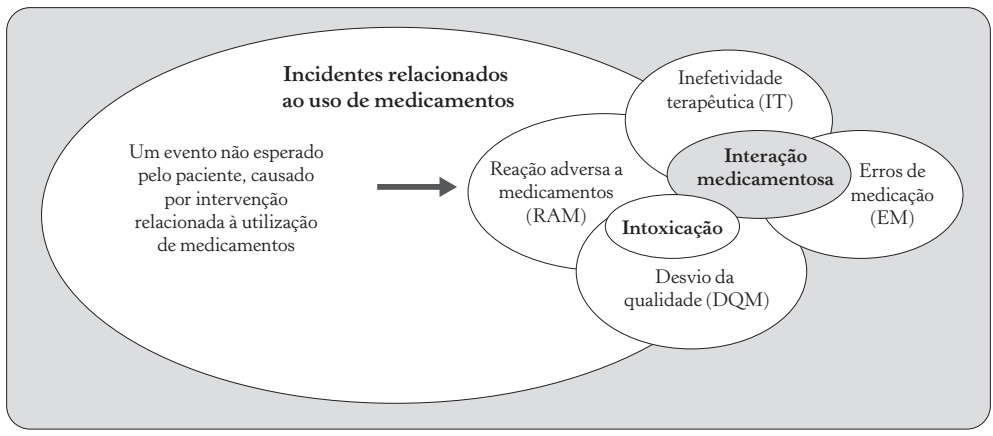

Fonte: Varallo; Mastroianni (2013b, p. 26-27); Anvisa (2009).

Deve-se prestar atenção especial quanto à prescrição e administração de medicamentos potencialmente perigosos (MPP). Estes devem ser monitorados com mais rigor, pois o uso indevido representa risco elevado de causar danos significativos aos pacientes. Estudos internacionais realizados com profissionais de saúde - médicos, enfermeiros e farmacêuticos -, observaram que 45\% $(n=354)$ dos profissionais participantes da pesquisa haviam utilizado pelo menos um medicamento potencialmente perigoso, sendo que $14,2 \%$ sofreram com algum erro decorrente de sua utilização nos últimos 12 meses, associado ao não cumprimento da técnica de medicação segura, denominada "5 certos": paciente certo, 
medicamento certo, dose certa, via certa e horário certo (Engels; Ciarkowski, 2015).

Esses incidentes são os mínimos a ser trabalhados em ambiente hospitalar em razão de sua alta incidência, principalmente no que se refere às reações adversas ao medicamento, que pode chegar em alguns casos a 97\% de ocorrência durante a internação hospitalar (Scripcaru; Mateus; Nunes, 2017).

\section{Erros de medicação}

Por definição, erros de medicação são quaisquer eventos evitáveis que podem levar ao uso inadequado de medicamentos. Dentre os processos que fazem parte do sistema de medicação e que podem ocasionar erros estão as etapas de prescrição, dispensação, preparo e administração de medicamentos (Cassiani, 2000). Portanto, em qualquer dessas etapas podem ocorrer falhas que resultem em dano ao paciente.

\section{Prescrição}

O ponto de partida para o uso de medicamentos é a prescrição. Erros relacionados a essa fase da cadeia medicamentosa que são considerados, por definição, uma decisão e redação não intencional da clínica médica, pode aumentar o risco de dano ao paciente decorrente de uma falha terapêutica associada ao uso de medicamento. Para evitar esses erros, a prescrição deve ser apropriada, com doses adequadas e tempo estabelecido para o tratamento, posologia bem definida e adequada aos fatores individuais, considerando as condições clínicas de cada paciente. Deve-se garantir que o medicamento prescrito seja eficaz, seguro e de qualidade (Cruciol-Souza; Thomson; Catisti, 2008; Feldman et al., 2017).

Prescrições com duplicidade terapêutica, incompletas, ilegíveis, com ausência de nomenclatura definida, uso de abreviaturas, erros 
na dose, frequência, via de administração e forma farmacêutica mostram os inúmeros exemplos de erros que uma prescrição pode conter. A prescrição de medicamentos é normatizada pelas Leis federais n. 5.991/73 e 9.787/99 e pela Resolução n. 357/01 do Conselho Federal de Farmácia (Brasil, 1973; Brasil, 1999; Brasil, 2001).

Embora a instituição de saúde desenvolva padronização de medicamentos por meio das diretrizes e políticas que a orientam quanto ao uso, fatores associados à falha na prescrição estão mais diretamente voltados à prática profissional.

Os erros de prescrição podem ser considerados pelos seguintes fatores:

Figura 4 - Esquema ilustrativo dos fatores contribuintes para erros de prescrição.

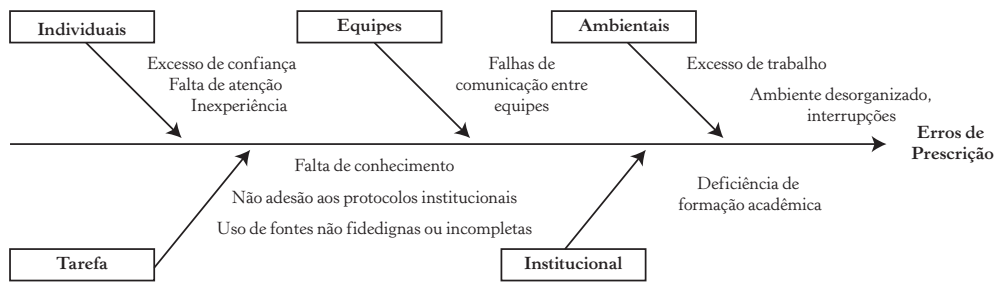

Fonte: Galiza et al. (2014); Madruga; Souza (2011).

\section{Distribuição}

Umas das atribuições da farmácia hospitalar é a distribuição de medicamentos mediante a solicitação da prescrição médica, realizada de forma segura e com prazos pré-determinados, promovendo o uso correto e racional dos medicamentos.

A distribuição envolve não só o recebimento da prescrição, mas também a certificação de sua integralidade antes de preparar ou autorizar a distribuição do medicamento. Para tanto, deve haver interpretação correta e avaliação para cada paciente conforme exigência clínica, além disso, quando da distribuição dos medicamentos, normas e procedimentos estabelecidos devem ser seguidos com o 
intuito de minimizar os erros de medicação. Profissionais capacitados e um ambiente seguro com mobiliário adequado auxiliam no processo de distribuição eficiente (Marin, 2003).

Há diferentes tipos de sistemas de distribuição utilizados no ambiente hospitalar, a saber: sistema de dose unitária, coletivo, individualizado direto e indireto e misto (Figura 5 e Quadro 15).

Um sistema adequado de dispensação de medicamentos deve proporcionar a redução de erros de medicação, uso racional de medicamentos e, consequentemente, redução de custos, controle das prescrições por meio da avaliação da farmacoterapia e segurança do paciente hospitalizado (Opas, 1997).

A escolha do método de sistema a ser empregado é um dos pontos-chave para garantia da segurança e bom funcionamento da farmácia quanto ao uso de medicamentos utilizados pelo paciente hospitalizado. Tendo como base estudos nacionais e internacionais, observa-se variações nas taxas de erros de distribuição em razão dos diferentes sistemas adotados.

Figura 5 - Esquema ilustrativo de sistema de distribuição de medicamentos por dose unitária.

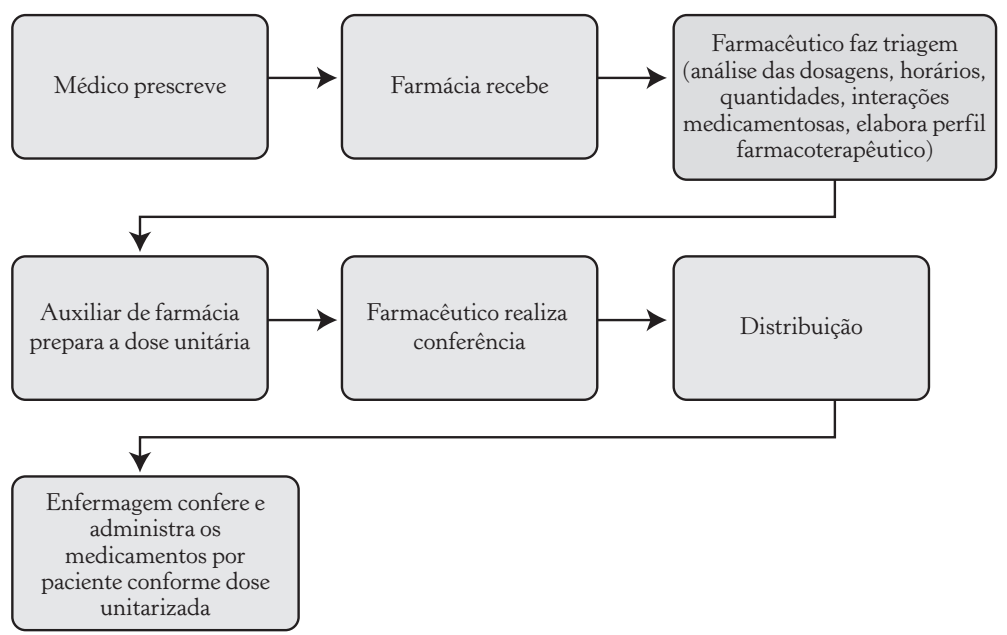

Fonte: Adaptado de Cavallini; Bisson (2002). 

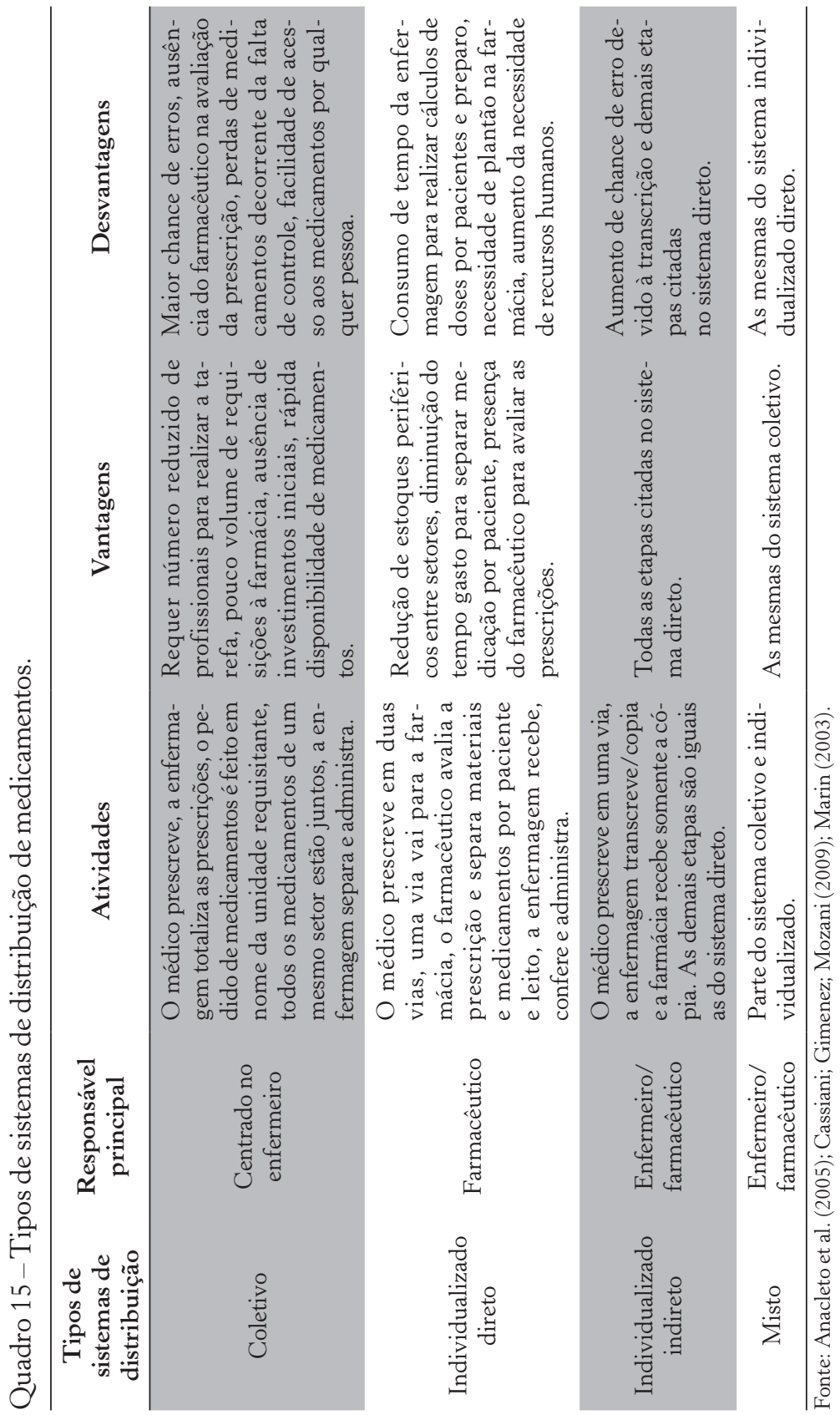
Há evidências de que o sistema unitarizado e informatizado é o mais seguro, pois o medicamento é distribuído na dose exata recomendada para cada paciente, permitindo à equipe de enfermagem a administração mais assertiva e segura, o que minimiza a ocorrência de riscos associados aos erros de medicação (Anacleto et al., 2005; Costa; Valli, 2008; European Directorate for the Quality and Safety of Medicines \& Healthcare, 2006; Gimenes et al., 2011).

A vantagem do sistema de dose unitária está na identificação de cada paciente no momento da distribuição, na redução de preparo de doses e na separação dos medicamentos um a um pela equipe de enfermagem, uma vez que a dose que o paciente deve receber é própria a ele. Também deve-se à autonomia e participação efetiva do farmacêutico na terapia do paciente, além do menor acúmulo de medicamentos em um só lugar.

Como desvantagem, tem-se o aumento de recursos de $\mathrm{RH}$ pela necessidade de contratação de pessoal qualificado para exercer a função, ou seja, recrutamento de mais funcionários pela instituição e treinamento da equipe da farmácia (Anacleto et al., 2005; Cassiani; Gimenes; Mozani, 2009).

Erros de distribuição são entendidos como desvios de uma prescrição médica ou do que é estabelecido pelos órgãos reguladores e pelas normas. Também podem ser caracterizados como

Quadro 16 -Tipos de erros na distribuição de medicamentos.

\begin{tabular}{cc}
\hline $\begin{array}{c}\text { Erros de } \\
\text { conteúdo }\end{array}$ & $\begin{array}{l}\text { Nome do medicamento errado; erros de concentração; for- } \\
\text { ma farmacêutica; dose excessiva; omissão de dose; medi- } \\
\text { camento com desvio da qualidade; dispensado por erros de } \\
\text { prescrição; data incorreta; instruções inadequadas; quan- } \\
\text { tidade incorreta. } \\
\text { Relacionados às informações impressas na embalagem } \\
\text { do medicamento pelo fabricante; etiquetas inseridas } \\
\text { na instituição hospitalar, como dados do paciente, } \\
\text { principalmente no que diz respeito aos medicamentos } \\
\text { potulagem }\end{array}$ \\
$\begin{array}{c}\text { Erros de } \\
\text { documentação }\end{array}$ & $\begin{array}{l}\text { Ausência de registros do processo de dispensação ou falha } \\
\text { no controle de registro da documentação. }\end{array}$ \\
\hline
\end{tabular}

Fonte: Anacleto; Perini; Rosa (2006); Costa; Valli (2008). 
discrepâncias entre a ordem escrita na prescrição e seu respectivo atendimento e podem receber diferentes classificações (Anacleto et al., 2010; Costa; Valli, 2008).

São vários os fatores determinantes que implicam erros de distribuição, sendo assim, é importante a utilização de indicadores relacionados à prática desse processo farmacêutico para o diagnóstico situacional e para a implementação de soluções efetivas de controle e práticas seguras.

Figura 6 - Esquema ilustrativo de fatores contribuintes para erros de distribuição.

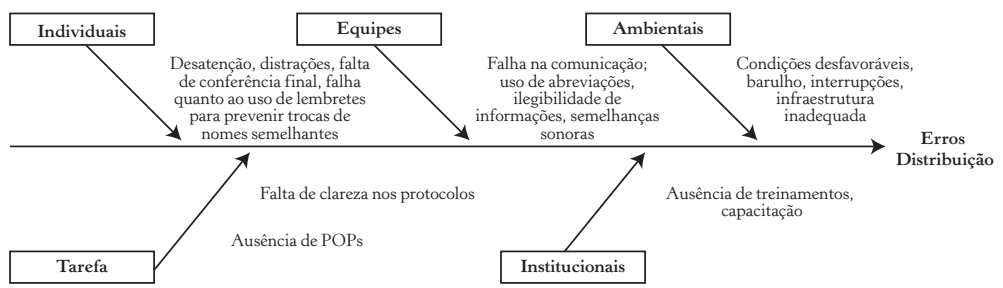

Fonte: Anacleto; Perini; Rosa (2006); Anacleto et al. (2005); Costa; Valli (2008)

Entre os processos de prescrição e distribuição ainda pode haver a etapa de transcrição. Atualmente esse procedimento é pouco utilizado, apesar de algumas instituições ainda manterem essa prática. Consiste na realização da cópia da prescrição feita pela equipe médica para a equipe de enfermagem, geralmente realizada por auxiliares ou técnicos. Um cópia da transcrição da receita é encaminhada à farmácia para dispensação e o original fica retido com a equipe médica e/ou de enfermagem. Esse procedimento traz inúmera desvantagens, além de ser um risco potencial para a ocorrência de algum incidente, uma vez que pode ocorrer transcrição errada do nome do paciente, do medicamento ou da posologia, além de outros dados importantes direcionados ao uso de medicamentos pelo paciente.

Com exceção de algumas especificações legais relacionadas ao preparo de medicamentos especificamente pelo profissional farmacêutico (Brasil, 2012; 1998), cabe também à equipe de enfermagem realizá-lo. Assim, o preparo e a administração de medicamentos são 
atribuições da enfermagem que merecem um olhar cuidadoso, pois erros nesses processos são considerados causas de incidentes em pacientes hospitalizados (Galiza et al., 2014).

\section{Preparo de medicamentos}

É a técnica de manipulação dos medicamentos que serão administrados ao paciente de acordo com a prescrição médica e distribuição anterior feita pela farmácia. É uma das atribuições da equipe de enfermagem e vem sendo considerada como um grave problema nos serviços de saúde em que o conhecimento técnico-científico e a experiência prática estão envolvidos. Fatores que favorecem a ocorrência de erros e incidentes relacionados ao preparo do medicamento podem ser:

Figura 7 - Esquema ilustrativo dos fatores contribuintes para erros de preparo de medicamentos.

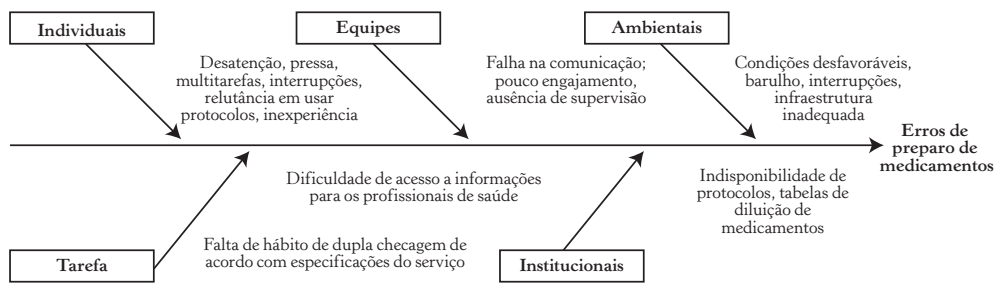

Fonte: Feldman et al. (2017); Galiza et al. (2014).

Administração de medicamentos

É a aplicação do medicamento propriamente dito ao paciente, após ser preparado e distribuído. Assim como o preparo de medicamentos, a administração requer conhecimentos técnico-científicos, éticos e legais para a execução do procedimento.

A administração de medicamentos é um dos procedimentos mais frequentes realizados pela equipe de enfermagem, que certamente é a que mais está envolvida em erros. O código de ética dos profissionais de enfermagem traz as responsabilidades dessa categoria e 
ressalta a função desses profissionais quanto à segurança do paciente, livre de danos decorrentes de imperícia, negligência ou imprudência. Diz ainda que é proibida a administração de medicamentos sem o conhecimento da ação e sem a certificação da probabilidade de riscos para o paciente (Brasil, 1987).

Falhas relacionadas às normas de biossegurança também podem ser caracterizadas como fator desencadeador de erros durante a administração de medicamentos (Feldman et al., 2017; Galiza et al. 2014).

Algumas causas de falhas que podem ocorrer e comprometer a administração correta do medicamento são observadas no esquema ilustrativo a seguir:

Figura 8 - Esquema ilustrativo dos fatores contribuintes para erros na administração de medicamentos.

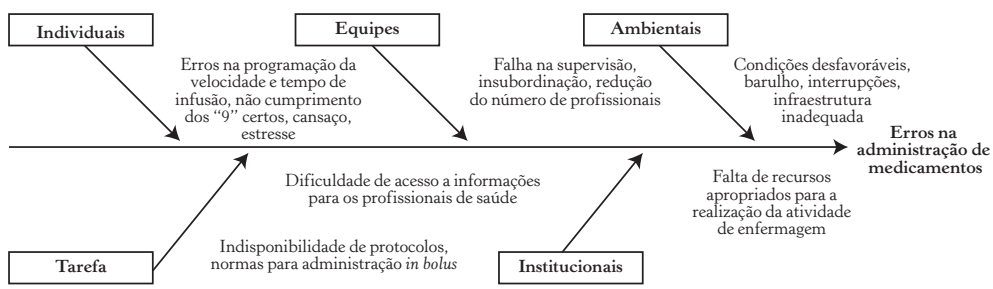

Fonte: Feldman et al. (2017); Galiza et al. (2014).

Figura 9 - Esquema ilustrativo dos "9" certos na administração de medicamentos.

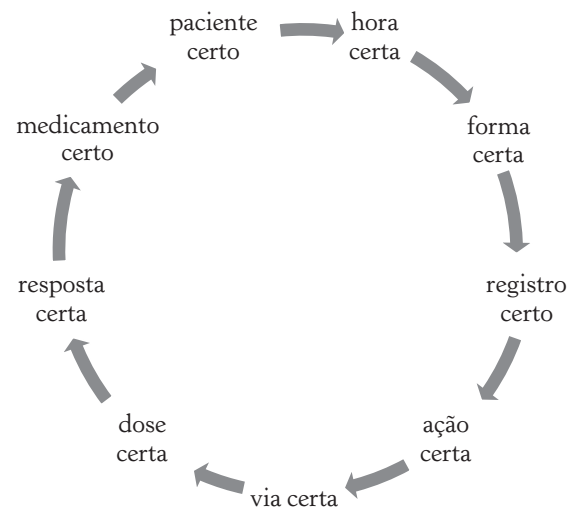

Fonte: Adaptado de Malcolm; Liu (2010). 


\section{Desvio da qualidade}

O desvio da qualidade dos medicamentos se dá por afastamento dos parâmetros de qualidade pré-estabelecidos para um produto ou processo (Brasil, 2010). São exemplos de desvios da qualidade as alterações organolépticas (mudança do odor, do sabor, da coloração, da turbidez), físico-químicas (precipitação, dificuldade de solubilização, homogeneização), além da presença de partículas estranhas, falta de informação no rótulo, fissuras nas embalagens, problemas de registro, vazamentos.

Embora se saiba que produtos e insumos farmacêuticos mal-acabados e com desvio de qualidade sejam resultantes do processo de fabricação da indústria farmacêutica, a conduta que um profissional assume perante esse problema merece destaque, no sentido de que pode ocorrer administração involuntária de medicamentos fora dos parâmetros adequados ao paciente, sujeitando-o a algum prejuízo de saúde por conta da baixa qualidade do produto, comprometendo, assim, todo o tratamento terapêutico, caracterizando a ação do profissional como erro de medicação.

A baixa ou má qualidade geralmente está associada à falha no controle de qualidade na linha de produção de medicamentos ou à qualidade insuficiente das matérias-primas dos fornecedores. A certificação do fornecedor, bem como o controle de qualidade são inerentes às Boas Práticas de Fabricação (Brasil, 2010). Apesar da regulamentação de funcionamento e o registro de medicamentos estar assegurados por lei em território nacional (Brasil, 1976), observa-se a prática ilegal de produção de medicamentos proibidos e falsificados, constituindo um problema de saúde pública no país.

Segundo a OMS, medicamento falsificado é um produto embalado e etiquetado indevidamente, de maneira deliberada e fraudulenta, em que não se respeita sua fonte ou identidade, podendo conter alterações e adulterações em sua fórmula original (OMS/ Opas, 2005a).

Estudo nacional observou que os medicamentos mais falsificados pertencem a diferentes classes terapêuticas, tendo maior procura 
para a compra indevida aqueles designados para tratamento da disfunção erétil, anabolizantes e os de custo mais elevado no mercado legal (Ames; Souza, 2012; Hurtado; Lasmar, 2014).

Medicamentos falsificados podem trazer graves consequências, tanto para quem os fabrica quanto para quem os utiliza, podendo causar prejuízos e agravos à saúde. A produção, distribuição e venda de medicamentos falsificados e sem registro são condutas previstas pelo Código Penal Brasileiro (Brasil, 1940) e pela Lei n. 11.343, de 23 de agosto de 2006 (Brasil, 2006) para medicamentos sujeitos a controle especial, conforme a Portaria n. 344 de 12 de maio de 1998 (Brasil, 1998a).

Conforme dados de 2015 do Pharmaceutical Security Institute (PSI), organização sem fins lucrativos que visa contribuir com a saúde pública na disseminação de informações a respeito da falsificação de medicamentos por meio de ações legais de autoridades públicas dos Estados Unidos, houve 3.002 incidentes relacionados à conduta farmacêutica ilegal, como a prática de falsificação e comercialização de medicamentos (PSI, 2017). Países como o Brasil, ocuparam o terceiro lugar no ranking de práticas ilegais naquele ano.

Três medidas de repreensão à falsificação foram propostas em 2003 no país, são elas: a obrigação de constar o número de lote em cada nota fiscal emitida para transporte, o cadastramento de todos os estabelecimentos de comércio de medicamentos na Anvisa e a capacitação de profissionais para a inspeção das vigilâncias sanitárias estaduais (Anvisa, 2004).

Dessa maneira, as notificações de desvios da qualidade podem ser utilizadas como um indicativo para avaliar as boas práticas de fabricação farmacêutica (Varallo; Mastroianni, 2013b). Cabe ao profissional de saúde possuir conhecimento suficiente para detectar um problema relacionado ao desvio da qualidade de medicamento, assim como deve ser fomentado, por parte da instituição de saúde, treinamentos e capacitação dos profissionais. 


\section{Inefetividade terapêutica}

A inefetividade terapêutica está relacionada com a ausência total ou parcial do efeito esperado, ou seja, da resposta esperada da terapia de um medicamento sob condições de uso previamente prescritas ou descritas em bula (Varallo; Mastroianni, 2013b). Isso pode ocorrer por problemas como desvio na qualidade do medicamento (DQM), erros de medicação (subdose, omissão, polimedicação levando a interações medicamentosas) ou ser inerente ao próprio organismo do paciente (polimorfismo genético).

Erroneamente, os DQMs são descritos como falhas de processos, devido à técnica de preparo inadequado ou alterações decorrentes do armazenamento incorreto, ou, ainda, pela precipitação de alguns medicamentos decorrente da utilização de diluente inadequado ou volume incorreto no preparo. Diante disso, torna-se necessária a investigação do real problema com a finalidade de levantar hipóteses e de assegurar se, de fato, foi um problema de fabricação do medicamento ou se houve falha no processo de preparo, manuseio e utilização, antes de se fazer uma notificação de desvio da qualidade (Capucho, 2008; Silva; Cornélio; Araújo, 2014), pois uma acusação falsa pode repercutir de maneira negativa, comprometendo a idoneidade da empresa fabricante do medicamento, assim quanto a credibilidade do programa de farmacovigilância da instituição hospitalar envolvida na notificação (Silva; Cornélio; Araújo, 2014).

Sabe-se, hoje, que existem variações genéticas que podem alterar a função de uma proteína que está envolvida na metabolização de um fármaco. De maneira geral, os medicamentos exercem efeitos farmacológicos através da modulação de atividades de enzimas e/ ou receptores. Assim, as variações genéticas, denominadas polimorfismos genéticos, podem alterar a atividade do alvo do fármaco, alterando também a resposta a esse fármaco.

Os medicamentos que inibem ou antagonizam uma enzima metabolizadora ou um receptor vão produzir maior resposta em uma dada dosagem em pacientes cujos polimorfismos genéticos conferem atividades mais altas da proteína-alvo. As concentrações do 
fármaco ativo ou seus metabólitos podem ser alterados no seu local de ação, levando a menor ou maior atividade da enzima metabolizadora, influenciando, assim, na resposta terapêutica (Shin; Kayser; Langafe, 2009).

Por exemplo, o metabolismo da varfarina, anticoagulante oral, é dependente da isoenzima CYP2C9*3. Indivíduos caucasianos que herdam os dois alelos que codificam essa enzima apresentam grande sensibilidade e necessitam de 80\% de redução da dose, enquanto em asiáticos essa variação não ocorre. Portanto, variações genéticas podem alterar tanto a fase farmacocinética quanto a farmacodinâmica de um medicamento, de tal forma que indivíduos de diferentes etnias podem ter metabolizadores lentos ou rápidos a certos medicamentos, sendo necessária a administração de doses mais baixas ou mais altas dos fármacos, para que se obtenha resposta terapêutica adequada e favorável ao paciente (Shin; Kayser; Langafe, 2009).

\section{Reação adversa a medicamentos (RAM)}

São definidas como qualquer evento nocivo e não intencional que ocorreu em decorrência da utilização de medicamento em doses normalmente usadas em humanos para finalidade terapêutica, profilática ou diagnóstica (OMS, 2005b). As RAMs podem ser classificadas de acordo com o mecanismo de produção do efeito, segundo a gravidade, frequência e causalidade.

Por definição, de acordo com a European Medicine Agency (EMA), são consideradas reações adversas os erros de medicação, uso de medicamentos sem autorização legal de comercialização, incluindo o uso indevido e o abuso (Emea, 2010).

A incidência global de RAM varia de 6,1\% a 18,1\% em pacientes já hospitalizados. É descrito que a RAM também prolonga o tempo de internação, além de elevar custos adicionais com tratamento (Sanchez; Amador; Plaza, 2014).

Os profissionais da saúde, principalmente aqueles que ficam na linha de frente com o cuidado do paciente em razão de sua estreita 
relação diária, são os mais aptos a reconhecer uma RAM ou suspeitar dela. No entanto, é preciso desmistificar que somente os farmacêuticos podem notificar uma RAM, apesar de estes profissionais estarem diretamente relacionados com o serviço de farmacovigilância, avaliando riscos e propondo melhorias para minimizar o evento.

As reações adversas, conhecidas como reações de hipersensibilidade ou reações imunológicas, são mais difíceis de serem prevenidas, pois constituem-se de uma idiossincrasia. Esses tipos de reações representam o foco principal da farmacoepidemiologia (Figueiredo; Alves, s.d.).

Há outros tipos de reações que são previsíveis, até mesmo aquelas sabidamente conhecidas e descritas em bula. Nesses casos, embora muitos profissionais acreditem que não se faz necessária a notificação, é importante realizá-la, pois permite acompanhar a frequência com que esses eventos acontecem, bem como reclassificá-los de acordo com a sua ocorrência.

A partir desses dados, o medicamento pode ser retirado do mercado ou, ainda, incluir novas informações em bula.

Quadro 17 - Classificação das RAMs quanto à frequência.

\begin{tabular}{ccc}
\hline Muito comum & $>1 / 10$ & $>10 \%$ \\
Comum (frequente) & $>1 / 100 \mathrm{e}<1 / 0$ & $>1 \% \mathrm{e}<10 \%$ \\
Incomum (infrequente) & $>1 / 1000 \mathrm{e}<1 / 100$ & $>0,1 \% \mathrm{e}<1 \%$ \\
Rara & $>1) 10.000 \mathrm{e}<1 / 1.000$ & $>0,01 \% \mathrm{e}<0,1 \%$ \\
Muito rara & $<1 / 10.000$ & $<0,01 \%$ \\
\hline
\end{tabular}

Fonte: Meyboom; et al. (1999).

Quadro 18 - Exemplos de medicamentos retirados do mercado pela Anvisa.

\begin{tabular}{ccc}
\hline Ano & Medicamento & Motivo da retirada \\
\hline 2000 & Fenilpropanolamina & $\begin{array}{c}\text { Risco de acidente vascular } \\
\text { cerebral (AVC). }\end{array}$ \\
2002 & Fenolftaleína & Risco de câncer \\
2003 & Tiratricol & $\begin{array}{l}\text { Risco de infarto agudo do } \\
\text { miocárdio (IAM) e AVC. }\end{array}$ \\
\hline
\end{tabular}




\begin{tabular}{|c|c|c|}
\hline Ano & Medicamento & Motivo da retirada \\
\hline 2004 & Rofecoxibe & $\begin{array}{l}\text { Risco de eventos } \\
\text { cardiovasculares. }\end{array}$ \\
\hline 2008 & Lumiracoxibe & Risco de problemas hepáticos. \\
\hline 2009 & Efalizumabe & $\begin{array}{l}\text { Risco de leucoencefalopatia } \\
\text { multifocal progressiva. }\end{array}$ \\
\hline 2010 & Rosiglitiazona & $\begin{array}{c}\text { Risco de ventos } \\
\text { cardiovasculares graves. }\end{array}$ \\
\hline 2011 & Anfepramona, femproporex & $\begin{array}{c}\text { Riscos à saúde e ausência de } \\
\text { comprovação científica de } \\
\text { eficácia. }\end{array}$ \\
\hline
\end{tabular}

Fonte: Anvisa (2012).

Certos fatores podem contribuir para a ocorrência de RAMs, como: falta de conhecimento em diferenciar seus mecanismos fisiológicos e patológicos; não certificação de que o paciente possui hipersensibilidade à medicamentos e mesmo assim prescrevê-los e administrá-los; deficiência ou carência de formação profissional para prever possíveis interações medicamentosas que possam favorecer a ocorrência de RAMs; não conhecimento da existência de reações prévias descritas relacionadas aos medicamentos. Quanto ao paciente, podemos citar: idade, gênero, comorbidade, polimedicação e automedicação (Varallo; Mastroianni, 2013b).

\section{Perda de dispositivos - Extubação acidental e perda de SNE e SVD}

A perda de dispositivos invasivos, tais como sondas nasoentéricas (SNE), nasogástricas (SNG), vesical de demora (SVD), tubos de respiração (tubo orotraqueais), cateteres venosos centrais, periféricos, arteriais, dentre outros, constituem-se ações acidentais ou não planejadas, não intencional, da retirada durante a fase de assistência à saúde.

Os fatores associados à perda de dispositivos estão diretamente relacionados à conduta de procedimentos, como cuidado à saúde, $\mathrm{e}$ 
são considerados indicadores da qualidade, devendo ter índice zero de ocorrência nas instituições hospitalares.

Em decorrência da perda de dispositivos, torna-se necessária a reintrodução do mesmo, podendo gerar desconforto ou algum incidente no processo de reinserção, contribuindo para um aumento na taxa de morbimortalidade, assim como aumento no tempo de internação e dispêndio de recursos por parte da instituição (Castellões; Silva, 2009).

A perda de dispositivos exige reflexão sobre as causas que levaram à ocorrência, não só pelo fato de ser considerado um never event quando resulta em óbito ou dano severo, mas por estar intrinsecamente relacionado à qualidade da assistência prestada, repercutindo na reputação da instituição.

Quadro 19 - Fatores contribuintes para perda de dispositivos.

\begin{tabular}{cl}
\hline Tipo de fator & \multicolumn{1}{c}{ Fator contribuinte ou influenciador } \\
\hline Paciente & $\begin{array}{l}\text { Condição clínica do paciente, agitação, oscilações de de- } \\
\text { lírio, idade. }\end{array}$ \\
\hline Tarefa & $\begin{array}{l}\text { Indisponibilidade de protocolos e planos de prevenção } \\
\text { para perda de dispositivos, uniformidade no cumpri- } \\
\text { mento das tarefas. }\end{array}$ \\
\hline $\begin{array}{c}\text { Individuais } \\
\text { (profissionais) }\end{array}$ & $\begin{array}{l}\text { Contenção física e química inadequada, falha duran- } \\
\text { te manuseio do paciente, fixação inadequada do dis- } \\
\text { positivo. }\end{array}$ \\
\hline $\begin{array}{c}\text { Equipes } \\
\text { Ambientais e de } \\
\text { trabalho }\end{array}$ & $\begin{array}{l}\text { Comunicação ineficaz. } \\
\text { trabalho. }\end{array}$ \\
\hline $\begin{array}{c}\text { Gestão } \\
\text { organizacional e } \\
\text { institucional }\end{array}$ & $\begin{array}{l}\text { Falta de ações, política, protocolos, campanhas de pre- } \\
\text { venção. }\end{array}$ \\
\hline
\end{tabular}

Fonte: Castellões; Silva (2009); Nascimento (2008); Santos; Lima (2015). 